\title{
Unusual enlargement of genial tubercle on cone beam computed tomography (CBCT): case report
}

\author{
Güldane Mağat ${ }^{1}$, Selçuk Hakbilen ${ }^{1}$, Sevgi Özcan Şener ${ }^{1}$, Alparslan Esen ${ }^{2}$ \\ ${ }^{1}$ Department of Oral and Maxillofacial Radiology, School of Dentistry, Necmettin Erbakan University, Konya, Turkey \\ ${ }^{2}$ Department of Oral and Maxillofacial Surgery, School of Dentistry, Necmettin Erbakan University, Konya, Turkey
}

\begin{abstract}
Enlargement of the genial tubercles, a group of four tubercles located at the inner part of symphysis menti, is very rare especially in dentulous patients. These may lead to problems in speaking, chewing, swallowing and further rehabilitation of the total prosthesis. A 39-year-old female patient was referred to the clinic for the assessment of general dental examination. The patient had difficulty in speaking and swallowing. When the floor of the oral cavity was examined, a bony expansion was detected on the lingual surface of the mandibular symphysis region. Panoramic radiography and cone beam computed tomography (CBCT) were performed. When images were evaluated, enlarged genial tubercle was observed only in CBCT but not in panoramic radiography. The patient was operated under general anesthesia and the enlarged genial tubercle was completely removed. In the post-operative period, speech and swallowing difficulties ceased to exist. To our knowledge, there is no other case reported with such long genial tubercles $(22 \mathrm{~mm}$ ) especially in a dentulous patient. We conclude CBCT is very useful in the diagnosis of enlarged genial tubercle exostosis and planning of the surgical procedure.
\end{abstract}

Keywords: cone beam computed tomography, enlargement, genial tubercle, mandible

Anatomy 2018;12(2):97-100 @2018 Turkish Society of Anatomy and Clinical Anatomy (TSACA)

\section{Introduction}

The genial tubercles consist of a group of four small bony elevations located located at the inner part of symphysis menti, midway between the superior and inferior borders of the mandible, and surrounding the lingual foramen bilaterally. ${ }^{[1]}$ The geniohyoid and genioglossus muscles are attached to the genial tubercles. The disfunction of these muscles is correlated with difficulty in chewing, speech and swallowing. ${ }^{[2]}$ Hence, the presence of an enlarged genial tubercle may lead to problems in normal speech, chewing and swallowing. In addition, it may lead to some problems in further rehabilitation of total prosthesis. In some cases, the enlarged genial tubercles may also cause recurrent ulcerations of mucosa or inhibit the use of prosthesis. $^{[3]}$
While two-dimensional (2D) in intraoral and panoramic radiographs are used essentially for oral hard tissues in dentomaxillofacial radiology, these can be visualized more accurately using cone beam volumetric tomography (CBCT) in three-dimension (3D) ${ }^{[4]} 3 \mathrm{D}$ imaging of normal and abnormal anatomical structures has important potential in diagnosis and planning of treatment. ${ }^{[5]}$

Enlargement of genial tubercles is very rare, especially in dentulous patients. This case report presents a genial tubercle enlargement in a dentate patient identified incidentally during a general dental examination, and highlights the importance of the benefit of CBCT in the diagnosis of enlarged genial tubercles and planning of the surgical procedure.

This case report was a poster presentation at the 2nd International Congress and 7th Scientific Meeting of Oral Diagnosis and Maxillofacial Radiology Society, April 13-15, 2017, Eskişehir, Turkey. 


\section{Case Report}

A 39-year-old dentulous female patient was referred to the Necmettin Erbakan University School of Dentistry Dental Clinic for general dental examination. The patient had difficulty with speech and swallowing. When the floor of the oral cavity was examined, a bony expansion was detected on the lingual surface of the mandibular symphysis region. In the panoramic radiograph, we did not observe any pathology in the anterior region (Figure 1). A CBCT scan was done for further investigation. When the images were evaluated in axial, sagittal and coronal planes, an overgrowth the genial tubercle was observed (Figures 2a-c).

The CBCT scan revealed an enlarged genial tubercle $12.8 \mathrm{~mm}$ wide and $14.59 \mathrm{~mm}$ high, extending $22.82 \mathrm{~mm}$ beyond the mandibular ridge. The morphometry of enlarged genial tubercles before and after the surgery is shown in Figures 3a-c. 3D reconstruction allowed volumetric visualization of the genial tubercle region before and after surgery (Figures $\mathbf{4 a}$ and $\mathbf{b}$ ).

The patient was well informed about the condition, its implications and treatment. The informed consent was obtained and surgical removal of the genial tubercle was planned under general anaesthesia and aseptic conditions. The enlarged genial tubercle was completely removed (Figures 5a-c). Histopathological examination revealed only bony particles. The patient was recalled for follow-up at regular intervals. In the post-operative period, the patient's speech and swallowing difficulties ceased to exist.

Written informed consent for the case to be published (including images, case history and data) was obtained from the patient for publication of this case report.

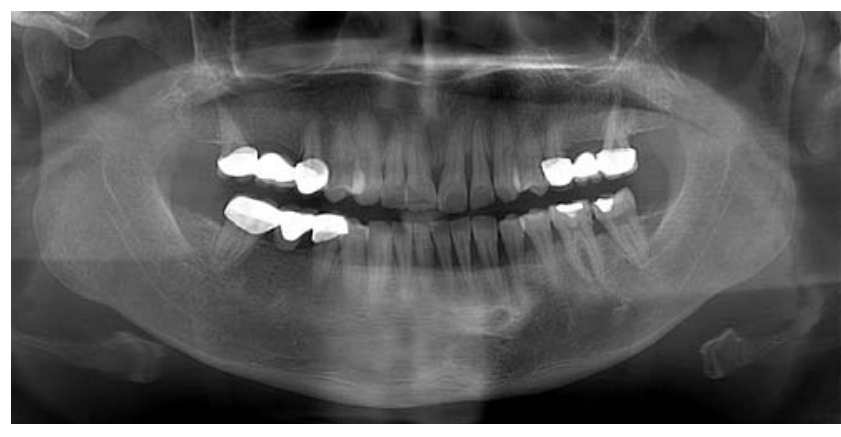

Figure 1. Digital panoramic radiography of the enlarged genial tubercles before surgery.

\section{Discussion}

The present case, using CBCT, demonstrated morphometric analysis of the enlarged genial tubercles in a dentulous patient. Genial tubercles are normally quite small with an average height $5.82 \mathrm{~mm}$ and average width 6.98 $\mathrm{mm} .{ }^{[6]}$ In addition to problems in normal speech, mastication, swallowing and inhibition of the use of the prosthesis, ${ }^{[7]}$ there are cases with spontaneous fracture and displacement of the enlarged genial tubercles in the literature. ${ }^{[1,2,8]}$ Surgical removal of enlarged genial tubercles is important in the repositioning of the genioglossus and geniohyoid muscles, so that the mandibula can adequately perform functions such as mastication, protrusion and normal speech.

The etiology of the enlarged genial tubercles is usually associated with edentulous mandibular bone loss, as a remodeling process following compressive forces and heavy loading on the alveolar bone due to imbalance of the denture. Mandibular alveolar bone generally resorbs four times higher than the maxillary alveolar bone. The masticatory force may lead to spontaneous fracture of the enlarged genial tubercles. ${ }^{[9]}$ Our patient was dentu-
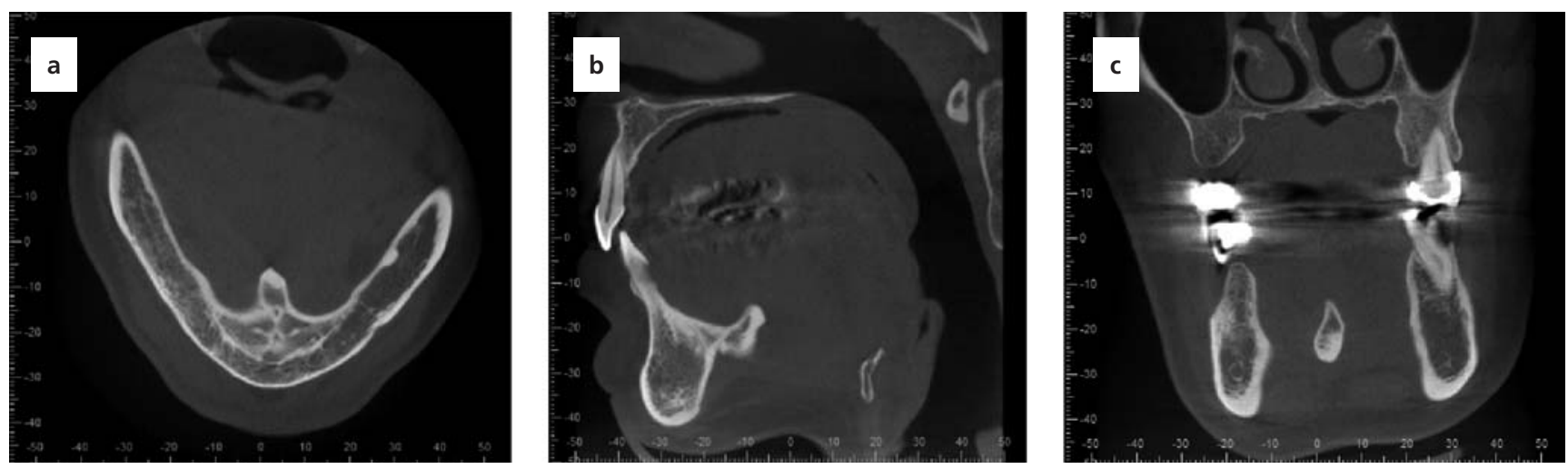

Figure 2. (a-c) Axial, sagittal and coronal $C B C T$ images of the enlarged genial tubercles. 

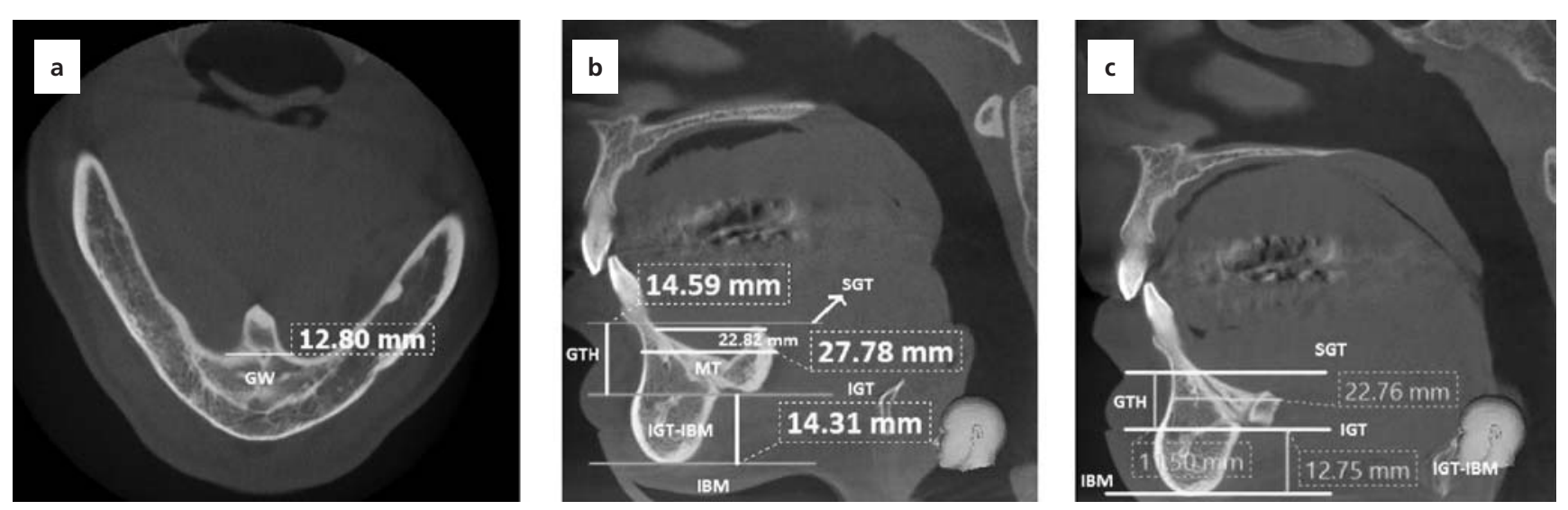

Figure 3. (a) Width of the enlarged of genial tubercles before the surgery. (b) Morphometric analysis of enlarged genial tubercles before the surgery. (c) Morphometric analysis of enlarged genial tubercles after the surgery. IBM: inferior border of the mandible; IGT: inferior border of genial tubercle; IGT-IBM: distance from IGT to IBM; GW: genial tubercle width; MT: anterior mandibular thickness; SGT: superior border of genial tubercle; SGT-IGT: distance from SGT to IGT.

lous with no trauma history and no previous radiographic documentation.

In the panoramic radiograph, the enlarged genial tubercles were not noticed due to superposition of other anatomical structures. CBCT images were used to observe and perform morphometric and volumetric analysis of the enlarged genial tubercles using 3D reconstruction. Therefore, we were able to exactly determine and measure the enlarged genial tubercles in this case.

An abnormal enlargement of the genial tubercles was first reported in 1955 in a mandible specimen of a Maori man, with a depth of $7 \mathrm{~mm}$, width of $13 \mathrm{~mm}$ and height of $9 \mathrm{~mm} \cdot .^{[10]}$ Yaed'u et al. ${ }^{[7]}$ and Gallego et al. ${ }^{[1]}$ reported cases with spontaneous fracture of the genial tubercles, diagnoses made using occlusal radiography and CT images, respectively. Yin et al. ${ }^{[6]}$ concluded that spiral CT measurements of the genial tubercles reflect their real anatomy which is important for the planning of a surgical procedure in the region.

The panoramic radiograph could not resolve the diagnosis itself due to the superimposition of structures. The authors highlighted the importance of occlusal radiography and CT scan for the evaluation of the genial tubercles. Rubira-Bullen et al. ${ }^{[8]}$ reported a genial tubercle $18 \mathrm{~mm}$ in length in an edentulous patient. Jindal et al. ${ }^{[3]}$ in 2015 reported that genial tubercles $11 \mathrm{~mm}$ wide and $21 \mathrm{~mm}$ long in an edentulous patient. They stated that the surgical removal of the genial tubercles is important in repositioning of the genioglossus and geniohyoid muscles.
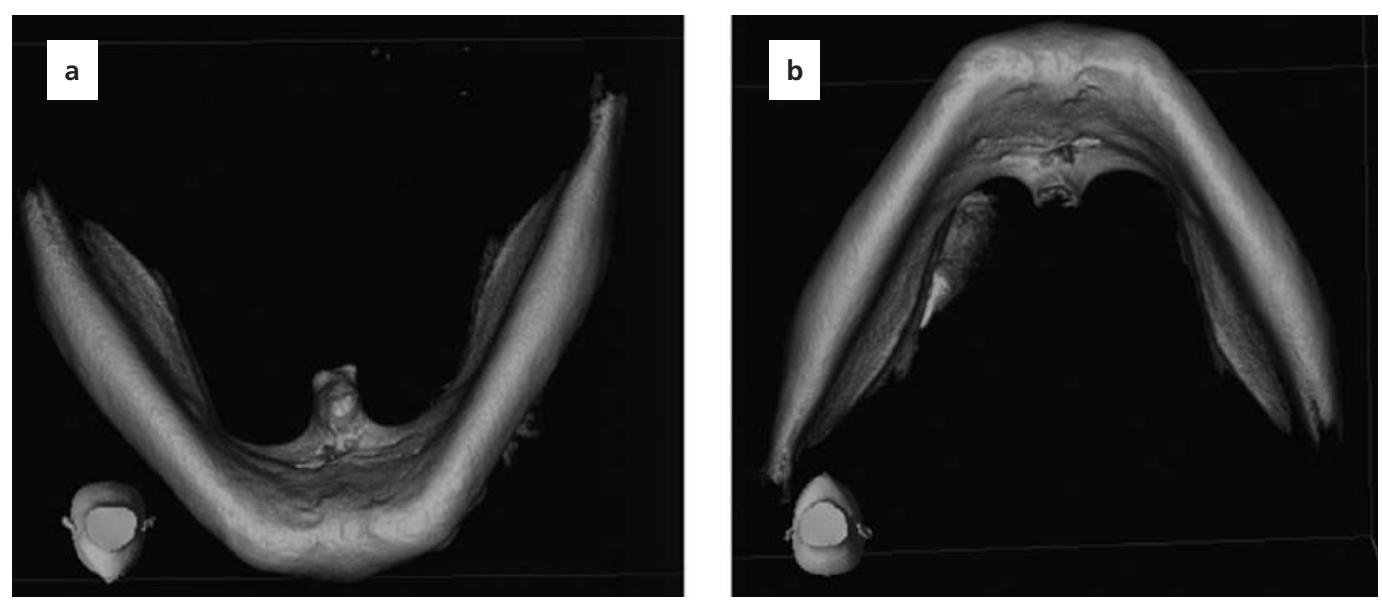

Figure 4. $(\mathbf{a}, \mathbf{b})$. 3D reconstruction images of the enlarged genial tubercles before and after surgery. [Color figure can be viewed in the online issue, which is available at www.anatomy.org.tr] 

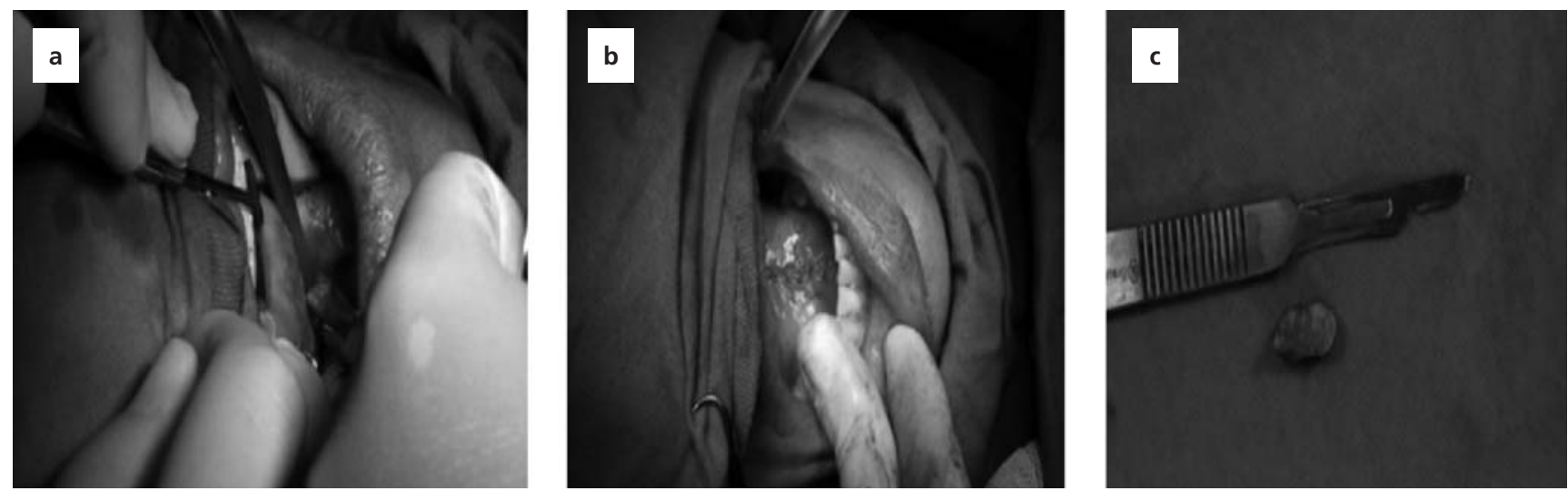

Figure 5. (a) Intraoral photograph during surgical operation of enlarged genial tubercles. (b) Post-operative photograph. (c) Extracted bone material. [Color figure can be viewed in the online issue, which is available at www.anatomy.org.tr]

In this case, we were able to perform an accurate measurement of the genial tubercles using CBCT images, as well as determining the exact position of the enlarged anatomic structure. $3 \mathrm{D}$ reconstructions in different views were also useful for the volumetric evaluation and spatial visualization of the mandible, as in the case reported by Rubira-Bullen et al. ${ }^{[8]}$ To our knowledge, there is no case reported in the literature with such long genial tubercles (22 $\mathrm{mm})$ especially in a dentulous patient.

\section{Conclusion}

Enlarged genial tubercles are very rare in dentulous patients. These may lead to various problems in speech and swallowing, and also in prosthetic rehabilitation leading to ulceration and bleeding. 3D imaging using CBCT is useful in diagnosis and planning the surgical procedure in cases with enlarged genial tubercles.

\section{References}

1. Goebel WM. Fractured genial tubercles. J Prosthet Dent 1978;39: $603-4$.

2. Shohat I, Shoshani Y, Taicher S. Fracture of the genial tubercles associated with a mandibular denture: a clinical report. J Prosthet Dent 2003;89:232-3.
3. Jindal G, Jindal S, Sharma P, Singla A. Rare enlargement of genial tubercles and its management: a case report. J Clin Diagn Res 2015; 9:Zd23-4.

4. Boeddinghaus R, Whyte A.Current concepts in maxillofacial imaging. Eur J Radiol 2008;66:396-418.

5. Kapila SD, Nervina JM. CBCT in orthodontics: assessment of treatment outcomes and indications for its use. Dentomaxillofac Radiol 2015;44:20140282.

6. Yin SK, Yi HL, Lu WY. Anatomic and spiral computed tomographic study of the genial tubercles for genioglossus advancement. Otolaryngol Head Neck Surg 2007;136:632-7.

7. Yassutaka Faria Yaedú R, Regina Fisher Rubira-Bullen I, Sant'Ana E. Spontaneous fracture of genial tubercles: case report. Quintessence Int 2006;37:737-9.

8. Rubira-Bullen I, Sant'Ana E, Yaedú RF, Tolentino ES, Borgo E. Rare enlargement of the genial tubercles. Enlargement of genial tubercles. Surg Radiol Anat 2010;32:415-6.

9. Santos-Oller JM, Junquera Gutierrez LM, De Vicente Rodriguez JC, Llorente Pendas S. Spontaneous fracture of hypertrophied genial tubercles. Oral Surg Oral Med Oral Pathol 1992;74:28-9.

10. Monheimer BM. Exostosis of the genial tubercles of the mandible. N Z Med J 1957;56:576.

11. Gallego L, Junquera L, Villarreal P, de Vicente JC. Spontaneous fracture of the mandibular genial tubercles. A case report. Med Oral Patol Oral Cir Bucal 2007;12:E599-601.

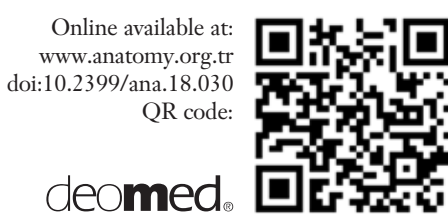

\author{
Correspondence to: Güldane Mağat, DDS, PhD \\ Department of Oral and Maxillofacial Radiology, School of Dentistry, \\ Necmettin Erbakan University, Konya, Turkey \\ Phone: +90 5059456157 \\ e-mail: gul_dent@hotmail.com \\ Conflict of interest statement: No conflicts declared.
}

This is an open access article distributed under the terms of the Creative Commons Attribution-NonCommercial-NoDerivs 3.0 Unported (CC BY-NCND3.0) Licence (http://creativecommons.org/licenses/by-nc-nd/3.0/) which permits unrestricted noncommercial use, distribution, and reproduction in any medium, provided the original work is properly cited. Please cite this article as: Mağat G, Hakbilen S, Özcan Şener S, Esen A. Unusual enlargement of genial tubercle on cone beam computed tomography (CBCT): case report. Anatomy 2018;12(2):97-100. 